\title{
The Application of Case Teaching Method in Computer English Teaching under OBE Mode_-Taking College English Blending Teaching of Hetao College as An Example
}

\author{
Congsen $\mathrm{Li}^{1, \mathrm{a}}$, Yunfei $\mathrm{Gu}^{1 *}$ \\ ${ }^{1}$ Hetao College (Bayannur City, Inner Mongolia, 015000)
}

\begin{abstract}
This article takes college English blending teaching in Hetao College as an example to analyze the concept of case teaching method under OBE mode. The author combines the application value of the case teaching method under the OBE mode and the current research on the current situation of computer English teaching to decompose the learning task. This article studies how to choose suitable teaching cases, how to guide students do well teamwork, how to improve the comprehensiveness of the assessment system, and how to reverse design the curriculum system. The author's purpose is to enhance the effectiveness of college English classroom teaching and enhance students' comprehensive learning ability.
\end{abstract}

\section{Introduction}

In the era of big data, high-speed computers and smart devices have become the basic means of knowledge transfer and information communication in human society. Whether it is the information connection between countries or the daily communication between people, it is almost inseparable from the help of electronic computers and smart products. Moreover, the relevant curriculum of computer English is a talent training strategy formulated by colleges and universities for the purpose of improving the English level of computer professionals and cultivating English translators in this field under the background of globalization. Teachers in colleges and universities integrate case teaching method into computer English teaching to improve classroom teaching effect and enhance students' learning enthusiasm.

\section{Conceptual Analysis of OBE Mode and Case Teaching Method}

\subsection{OBE Mode}

OBE is the abbreviation of Outcomes-based Education in English. It refers to an education model based on learning output, also known as outcome-oriented education. It first appeared in the basic education reforms in the United States and Australia. Throughout the course of teaching, educators should clarify their teaching goals. At the same time, preliminary predictions should be made of students' learning outcomes. For example, teachers should analyze the English vocabulary and phrase level requirements of talents involved in computer technology, such as programming, data analysis, or computer language, according to the market before the start of computer English course teaching. Furthermore, educators should also set up and implement teaching links in the learning process according to the learning characteristics of students. Different from the traditional indoctrination model, students should be the protagonists of the entire classroom. They are supposed to know clearly "what do they need to do", "which task they need to be completed?" and "how to work with group members to complete the work." Teachers only perform the duties of inspiration and control. Finally, after the students complete the task, the teacher should design a student-centered evaluation mechanism with multiple participation (teacher-student evaluation, student-student evaluation, and enterprise evaluation) to maximize the teaching effect.

\subsection{Case Teaching Method}

Case teaching method means that the teacher chooses the matching case according to the actual educational task, and uses the actual case to guide the students to think independently, so as to deepen the students' learning impression. Judging from the actual application situation, the currently widely used case teaching methods mainly include the following types. The first is the analysis and understanding type. This type of case means that when the teacher presents the case, he will also put forward the corresponding case problemand problem solving method. Teachers help students understand some concepts or ideas in a question-led way. The second is the evaluation and decision-making type. In this type of case, the teacher will also propose at least three corresponding case solutions when presenting the case. Then, students rank the rationality of the problem-solving methods in a group or 
individual way in order to find the optimal solution. The third type is to draw inferences from one another. In this type of case, the teacher will also put forward the corresponding case solution and the problems faced when the case is presented. This is conducive to helping students complete the construction of the knowledge system, so that students have the ability to solve other similar problems. Thereby, it also enhance the practical value of case teaching.

\section{The Application Value of Case Teaching Method in OBE Mode}

\subsection{Help Students Understand Difficult Knowledge Points}

As shown in Table 1, in the process of computer English vocabulary learning, there are many professional vocabulary, which are also the basic conditions for computer English learning. In the OBE mode, reasonable application of case teaching method can be used to combine these professional terms with actual cases. For example, combining priority queues with computer programming language cases, teachers use cases to explain these content, so as to improve students' learning impression of the course content. This will not only help students fully understand the meaning of the vocabulary they learn in subsequent use, but also help improve the reliability of the analysis results [1].

Table1. Proprietary vocabulary in computer English

\begin{tabular}{|c|c|c|c|}
\hline $\begin{array}{c}\text { Algorithm } \\
\text { Term }\end{array}$ & $\begin{array}{c}\text { Related } \\
\text { English }\end{array}$ & $\begin{array}{c}\text { Computer } \\
\text { term }\end{array}$ & $\begin{array}{c}\text { Related } \\
\text { English }\end{array}$ \\
\hline $\begin{array}{c}\text { Priority } \\
\text { Queue }\end{array}$ & $\begin{array}{c}\text { Priority } \\
\text { Queue }\end{array}$ & Port & Port \\
\hline $\begin{array}{c}\text { Matrix } \\
\text { multiplication }\end{array}$ & $\begin{array}{c}\text { Matrix } \\
\text { multiplication }\end{array}$ & Server & Server \\
\hline $\begin{array}{c}\text { Greedy } \\
\text { Algorithm }\end{array}$ & $\begin{array}{c}\text { Greedy } \\
\text { Algorithm }\end{array}$ & $\begin{array}{c}\text { Open } \\
\text { system }\end{array}$ & $\begin{array}{c}\text { Open } \\
\text { system }\end{array}$ \\
\hline $\begin{array}{c}\text { Network } \\
\text { security }\end{array}$ & $\begin{array}{c}\text { Network } \\
\text { security }\end{array}$ & $\begin{array}{c}\text { Guide } \\
\text { disc }\end{array}$ & $\begin{array}{c}\text { Guide } \\
\text { disc }\end{array}$ \\
\hline
\end{tabular}

\subsection{Improve Students' Autonomous Learning Ability}

In order to improve students' employability, Hetao College teachers need to focus on cultivating students' autonomous learning ability in the process of computer English teaching. Moreover, in actual teaching, teachers should also use some application cases to help students understand proper nouns or other vocabulary. Finally, in subsequent case applications, students can flexibly apply these vocabulary to the system. This not only improves the practicality of computer English, but also improves the stability of the system operation process [2].

\subsection{Keep Students' Learning Interest}

As shown in Table 2, in the learning process of computer
English, There are many extensions and derivative words we need to learn. However, in specific learning, the learning of these vocabulary is relatively boring. Therefore, if teachers want students to complete these vocabulary learning, teachers need to adopt effective measures to maintain students' interest in learning. In the practical application of the case analysis method, with the help of some interesting application cases, the students' interest in the course content can be maintained. In addition, with the help of the teaching of these practical cases, students can maintain a higher interest in learning. In such a learning process, not only students can complete applied learning in a short time, but also the application value and reliability of the system itself will be improved [3].

Table2. The Use of Extensions and Derivatives in Computer English

\begin{tabular}{|c|c|}
\hline Extend & Derive \\
\hline Hub & De+bug=Debug \\
\hline Swithch & explor+er=Explorer \\
\hline Router & narrat+or=Narrator \\
\hline Network Bridge & Subnet + mask=Subnetmask \\
\hline
\end{tabular}

\section{Analysis of the Current Situation of Computer English Teaching in Hetao College}

\subsection{Unclear Teaching Goals}

From the current situation of computer English teaching in Hetao College, it can be found that there is a problem of unclear teaching objectives in the specific case teaching application stage. For example, in the learning process of the content of matrix multiplication, teachers need to carry out detailed analysis of these content. Moreover, the teacher's teaching focus should be placed on the learning and practice of teaching content. However, many teachers only explained the teaching theory, and did not pay attention to explaining its related practical content. Therefore, this leads to the result of low clarity of the teaching target learning content, and also reduces the classroom learning effect [5].

\subsection{Less Applicability of Selected Case}

When choosing a case, the teacher needs to associate it with the content of the teaching. However, in practical applications, the cases selected by teachers are poorly targeted and cannot meet the established requirements. Moreover, there is still a low adaptability in case selection. Although the basic language of computer English has not changed much, the computer system has been updated and its coding rules have also changed. However, the case selected by the teacher has no practical value, which also reduces the enthusiasm of students to study the course [6]. 


\subsection{Bad Classroom Teaching Atmosphere}

In addition to the above application problems, there is also a problem of poor teaching atmosphere in the actual process. In the process of computer English learning, students need to learn many extensions and derivative words. However, the learning of these vocabulary is relatively boring. Judging from the teaching situation of Hetao College, the methods it adopts are mainly the teaching method that integrates theory and practice. This teaching method has a higher degree of freedom in the teaching process, and students' learning enthusiasm in this process is lower, which reduces the efficiency of classroom learning [7].

\section{The Specific Application of Case Teaching Method in Computer English Teaching under OBE Mode}

\subsection{Specific Learning Task}

Decomposing learning tasks can gradually improve students' learning ability and the effect of computer English teaching. Combined with the basic situation of Hetao College, in the specific learning process of computer English basic vocabulary, teachers can divide it into elementary vocabulary, intermediate vocabulary and advanced vocabulary, and use the order of teaching from easy to difficult to complete the learning task. Moreover, teachers should also do a good job of collecting information in the course teaching, and adjust the followup course teaching courses in time to improve the rationality of the teaching content [8].

\subsection{Choose Suitable Teaching Case}

By choosing appropriate teaching cases, the adaptability of teaching content can be improved. In addition, this is also conducive to give full play to the advantages of resultoriented education, thereby enhancing the teaching effect of classroom content [9]. In the specific application process, teachers can fully integrate the vocabulary content and the current computer system development. Subsequently, the reliability of these contents is analyzed, and the application structure is adjusted, and the teaching process is drawn up, so as to improve the applicability of the teaching case itself and increase students' interest in learning the content of the course.

\subsection{Guide Students to Teamwork}

Teachers need to cultivate students' team learning ability during course learning. Teachers can guide students to teamwork through suitable cases and questions, which can improve students' comprehensive learning ability, thereby enhancing the application ability of the system itself. In practical applications, teachers can use evaluation and decision-making cases to put forward at least three corresponding case solutions while presenting cases. Then, students sort the rationality of the problem-solving methods in a group to find the best solution. Teachers can use this method to cultivate students' learning ability [10].

\subsection{Improve the Comprehensiveness of the Assessment System}

Improving the comprehensiveness of the assessment system can help teachers understand the current teaching situation in a timely manner, and provide reliable data references for the adjustment of subsequent teaching tasks. In the specific application process, teachers can use information technology to build an evaluation system, and use practical and theoretical evaluation methods to improve the reliability of the final evaluation results. It should be noted that, in view of the strong practical characteristics of computer English, Hetao College should pay attention to the screening of assessment content and rationally evaluate the scores to improve the accuracy of the assessment results [11].

\subsection{Reverse Design Curriculum System}

Do a good job in reverse designing the curriculum system to meet the application requirements of the teaching model. In addition, taking the needs of students as the starting point is conducive to optimizing the training goals of students, improving the students' own comprehensive ability and the reliability of the curriculum results. Moreover, in the design of the curriculum system, teachers also need to avoid blindness and randomness in setting the results. Furthermore, teachers also need to do a good job in the evaluation of the curriculum system in order to improve the efficiency of resource utilization and the teaching efficiency of computer English courses[12].

\section{Conclusion}

In summary, decomposing learning tasks can gradually improve students' learning ability; choosing appropriate teaching cases can improve the adaptability of teaching content; guiding students to teamwork can improve students' comprehensive learning ability; reverse designing the curriculum system can meet the application requirements of the teaching mode. By applying the case teaching method to computer English teaching, it is helpful to improve the course teaching effect and students' comprehensive ability.

\section{Acknowledgement:}

Funds from Hetao College teaching and research program: Research and Practice of Teaching Mode on College English Blending Teaching in Application Oriented Universities_- Taking Hetao College as An Example. Program number: HTXYJY18013;

Funds from Inner Mongolia Academy of Social Sciences in 2019 Foreign Language Special Project: Model of SPOC For College English under the Guidance of China Standards of English. Program number: YZX201926 


\section{References}

1. Jia Lingli. The application of case teaching method in the teaching of ideological and political courses in secondary vocational schools $[\mathrm{J}]$. Scientific Consulting (Technology· Management), 2020(08): 191.

2. Chang Zhihui, Ren Yue, Liu Zhaoyu. The application of task-driven case teaching method in interventional radiology clinical practice $[\mathrm{J}]$. Continuing Medical Education, 2020, 34(07): 13-15.

3. Jin Lei, Zhou Xinmiao, Zhang Jing. The application status of case teaching method in China's MBA education and the analysis of its problems: questionnaire survey and interview data based on the dual perspectives of teaching and learning[J]. Graduate Education Research, 2020(04) ): 66-71.

4. Zhang Yaping, Wang Chongxian. "Curriculum Ideology" in applied undergraduate colleges from the perspective of OBE concept[J]. Automotive Practical Technology, 2020(14): 210-212+218.

5. [5]Guo Yiran. Cultivation and Practice of Talents in Drama, Film and Television Literature under the OBE Concept[J]. Media Forum, 2020, 3(17): 138-139.

6. Tian Na, You Caiyin, Tang Yufei, Zhao Kang. The innovation and practice of the non-technical ability training model of materials majors under the OBE concept[J]. High Education Journal, 2020(22): 41-43.

7. Gong Yongzhen, Zhong Chengfu, Wang Fuying, Huang Chonglin, Huang Yongsheng. Exploration of the reform of mechanical design and manufacturing and its automation professional production practice based on OBE model[J]. High Education Journal, 2020(22): 48-50+ 54

8. Zhang Caili, Song Ti, Sun Jishu, Ma Shibin. Design of OBE education model for economics and management courses of road bridge and river crossing engineering under the background of new engineering disciplines[J]. High Education Journal, 2020(22): 8083.

9. Zong Lina, Wang Xiangpeng, Zheng Yunxiang. Reform and practice of the examination mode of physical chemistry courses in applied undergraduate colleges based on the OBE concept[J]. Chemistry Education (Chinese and English), 2020, 41(14): 1419.

10. Liu Xiaobing, Yu Yaliang, Liu Fang. Teaching design and optimization of economics and management courses in urban agriculture and forestry colleges under the OBE concept $[\mathrm{J}]$. Anhui Agricultural Science Bulletin, 2020, 26(13): 159-161.

11. Xu Xuelin, Cai Wenpei, Yang Teng. The teaching reform of 8086 microcomputer principle course under the result-oriented education concept[J]. Computer Education, 2020(07): 152-156.

12. Chen Yi. The application of case teaching method in computer English teaching under OBE mode[J]. Journal of Shaanxi Youth Vocational College, 2019(04): 42-46. 